Paper ID \#17738

\title{
Gaining the Competitive Edge in Proposal Submission to the National Sci- ence Foundation Advanced Technological Education Program (NSF-ATE): Mentor-Connect
}

\author{
Ms. Elaine L. Craft, Florence-Darlington Technical College
}

Elaine L. Craft (Florence-Darlington Technical College, Florence, SC) holds a baccalaureate degree in chemical engineering from the University of Mississippi and a MBA from the University of South Carolina with additional graduate studies in mathematics. Her experience includes working as an engineer in industry as well as teaching and administration at community college and state levels. Since 1994, she has served as Executive Director of the South Carolina Advanced Technological (SC ATE) Center of Excellence, leading initiatives and grant-funded projects to develop educational leadership and increase the quantity, quality and diversity of highly skilled technicians to support the American economy. Craft currently serves as Principal Investigator (PI), Mentor-Connect: Leadership Development and Outreach for ATE; PI, South Carolina National Resource Center for Expanding Excellence in Technician Education (SCATE); Co-PI, ATE Regional Center for Aviation and Automotive Technology Education Using Virtual E-Schools (CA2VES); and Co-PI, Centers Collaborative for Technical Assistance (CCTA). The SC ATE Center is widely known for developing and broadly sharing successful educational models and practices in technician education focused on faculty development; problem-based learning curricula; mentoring; industry partnerships; student recruitment and success; research and evaluation; mentoring other technician educators nationally to broaden the impact of the National Science Foundation Advanced Technological Education Program; and, developing STEM faculty leaders.

\section{Prof. Karen Wosczyna-Birch, CT College of Technology}

Dr. Karen Wosczyna-Birch is the Executive Director and Principal Investigator of the Regional Center for Next Generation Manufacturing, an National Science Foundation Center of Excellence. She is the state director for the College of Technology, a seamless pathway in technology and engineering from all 12 public community colleges to 8 public and private universities. Dr. Wosczyna-Birch has expertise with both the recruitment and persistence of under represented populations, especially women, to pursue careers in engineering and technological disciplines. She has presented at numerous conferences throughout the United States and was an invited speaker at the international Gender Summit in Belgium in 2016.

\section{Mrs. Charlotte B. Forrest,}

Charlotte B. Forrest currently serves as Project Manager and Co-Principal Investigator for the National Science Foundation (NSF), Advanced Technological Education (ATE) funded program-Mentor-Connect: Leadership Development and Outreach for ATE project DUE\#1204463 and DUE\#1501183 since April 2013. She works in Florence, SC at Florence-Darlington Technical College in the South Carolina Advanced Technological Education (SC ATE) National Center of Excellence. She holds a Bachelor of Science from the University of Louisville and earned her Master's degree in Adult and Higher Education from Morehead State University. A native of Louisville, KY, she has an array of experience in student affairs, STEM/ diversity initiatives and a passion for initiatives that encourage diversity and the representation of those underserved or underrepresented in sciences, technologies, engineering and mathematics fields, community colleges and higher education, in general. She is a member of the National Society of Black Engineers (NSBE) and Society of Women Engineers (SWE). 


\title{
Gaining the Competitive Edge in Proposal Submission to the National Science Foundation Advanced Technological Education Program (NSF-ATE): Mentor-Connect
}

\begin{abstract}
Securing external funding to improve or expand engineering technology and related programs is increasingly essential as state funding for two-year technical and community colleges plummets nationwide. Grants often provide the impetus and means for innovation that would not otherwise be possible. The National Science Foundation Advanced Technological Education (NSF-ATE) program has a unique focus on two-year colleges and technician education. However, the funding rate for the program recently declined to $22 \%$ and the proposal submission process is complex. NSF also has an agency-wide mission to encourage diverse populations to participate in science, technology, engineering, and mathematics (STEM). The Mentor-Connect: Leadership Development and Outreach Initiative for ATE project, NSF DUE \#1204463 and \#1501183 awarded to Florence-Darlington Technical College, Florence, South Carolina, offers an efficient way for prospective principal investigators to learn effective proposal preparation strategies specific to this funding program and to receive cost-free assistance that helps them gain the competitive edge. Mentor-Connect also addresses NSF's diversity goals.
\end{abstract}

As a leadership development and outreach project for NSF-ATE, the project uses a threepronged approach to support potential grantees. It offers mentoring, technical assistance, and digital resources. The project's immediate goals are to help STEM faculty prepare competitive grant proposals and to improve their colleges' institutional capacity for obtaining grants. Its longterm goal is to develop a new generation of STEM faculty leaders.

Early evidence indicates that this project is increasing the geographic diversity of colleges submitting proposals to the NSF-ATE program. The 99 colleges in the first 5 project cohorts are from 31 different states. Each participating college is located in a geographic area where there has been either no previous NSF-ATE grant awards or none in the past 10 years. There is also evidence of improvements in the quality of NSF-ATE proposals as a result of this project. More than $89 \%$ of the 79 colleges in the first 4 cohorts of participating colleges submitted NSF-ATE grant proposals; 36 of them or $69 \%$ have been awarded grants of approximately $\$ 200,000$ each. The average acceptance rate for colleges that have applied to participate in the project is $65 \%$. This paper documents the project's unique combination of strategies and the competitive edge that those strategies provide for prospective NSF ATE grantees.

Introduction

Educational programs in general are vital to the success of the economy. Even more so are technical education programs that equip students with the science, technology, engineering, and math (STEM) skills needed to address the growing workforce challenge. However, since the Great Recession, "Trends in total institutional revenues for community colleges indicate significant shifts toward external revenue sources and away from core state and local funding for basic operations" (Merisotis \& Wolanin, n.d.). In response to this, "colleges and university systems across the states have eliminated administrative and faculty positions (in some instances replacing them with non-tenure-track staff), cut courses or increased class sizes, and in some 
cases, consolidated or eliminated whole programs, departments, or schools" (Mitchell \& Leachman, 2015). Amid budget cuts, grants have become even more important as funding sources for new, innovative programs at public two-year colleges. The National Science Foundation Advanced Technological Education (NSF-ATE) program is a highly competitive program with a unique focus on two-year colleges and technician education. However, relatively few community college and technical college educators have experience seeking competitive grants or are aware of the NSF-ATE funding opportunity.

As a leadership development and outreach project for NSF-ATE, the one-of-a kind MentorConnect project offers an efficient way for prospective principal investigators to learn effective proposal preparation strategies for this program and to receive cost-free assistance that helps them gain the competitive edge. It also addresses NSF's diversity goals.

\section{Background}

NSF developed the ATE program in response to the Scientific and Advanced Technology Act of 1992. This Congressional mandate directed the federal science agency to utilize associatedegree-granting colleges to improve the quality of technicians for advanced technology fields that are important to the nation's security and competitiveness (National Science Foundation, 2016). The program requires that two-year college educators have leadership roles in funded projects and that educators partner with employers.

Current grants support the development of technicians and the educators who teach them in advanced manufacturing, agriculture and biotechnologies, energy and environmental technologies, engineering technologies, information technologies, micro and nanotechnologies, and security technologies. The program also supports STEM learning in general, evaluation of NSF-ATE initiatives, and technician-related educational research (ATE Central, n.d.). In 2015, NSF-ATE initiatives, which are pilot tests of a wide array of curricula and pedagogical innovations, educated 112,010 students, developed 2,530 curriculum materials, and offered 2,120 professional development opportunities (Wilson, Wingate, Lee, \& Gullickson, 2016).

The unique project is designed to 1) fill the void created by NSF's elimination of the preliminary proposal review process for the ATE program in 2012; 2) address the challenge that approximately two-thirds of the nation's 1,123 community colleges have never received NSF funding; 3) better manage the rapidly growing number of requests received by ATE center principal investigators and NSF program officers related to grant proposal development and project management ; and 4) most importantly, develop grant writing and leadership skills among STEM faculty members at two-year colleges.

The Mentor-Connect project resulted from a comprehensive planning process that involved NSFATE principal investigators, NSF-ATE program officers, potential NSF-ATE grantees, the National Academy of Engineering, the American Association of Community Colleges, and IBM Corporation. It is modeled on IBM's award-winning Global Mentoring Program (Murrell, ForteTrammell, \& Bing, 2008).

In its translation of the IBM mentoring model, the project aims to 
- recruit talented STEM faculty from institutions previously not funded by NSF-ATE,

- involve diverse individuals and institutions in the NSF-ATE community,

- expand access to the knowledge and expertise of experienced NSF-ATE principal investigators, and

- support knowledge transfer and retention of the NSF-ATE program's institutional wisdom from experienced ATE principal investigators to new generations of principal investigators.

Method

The project's three-pronged approach involves mentoring, technical assistance, and digital resources. At its core the project involves one-on-one mentoring of selected faculty by experienced NSF-ATE principal investigators. The project also purposefully leverages the talents of individuals from within the NSF-ATE community and mentors who are some of the program's most experienced and successful principal investigators. Its technical assistance comes primarily through the grant-writing training that Mentor-Connect personnel provide during in-person workshops, webinars, and in their responses to help-desk queries. Its digital resources include a key-word searchable digital library collection of information specific to preparing and submitting NSF-ATE proposals. The combination of just-in-time instruction and on-going assistance provided by the project team is designed to build capacity among community colleges to prepare and submit competitive NSF-ATE proposals. Longer term, the project intends to be a regenerative mentoring system to develop STEM faculty leaders among those who become principal investigators and co-principal investigators. The project specifically targets colleges that are new to ATE, but the help desk and digital resources are available to all aspiring NSF-ATE grantees.

In their role as advisors, mentors are expected to

- provide feedback on grant proposal topics and proposal components,

- help the proposal writing team refine ideas and strategies, and

- provide referrals to ATE resources.

Mentees are expected to

- initiate and maintain regular contact with the mentor,

- ensure regular communication with college team members, and

- coordinate activities among campus stakeholders to meet proposal submission requirements and timelines.

The unique project also provides advice to mentors and selected mentees (project teams that the Mentor-Connect project serves), in the form of guidelines (See Appendix A - B). Mentors' advice guidelines include, but are not limited to the following: "Reinforce role boundariesbeware of taking on the mentees' institutional problems. [Help mentees] figure out how to best address and resolve issues that arise that affect their project and proposal, rather than fixing it yourself." The 10 points of advice for mentors close with the following: "Content-remember the overriding project and NSF-ATE project goal is to help colleges develop or strengthen technician training programs in science, technology, engineering, and mathematics fields by developing a project that merits NSF funding. Good proposals tell a consistent story 
complemented by clear, specific, and achievable goals, objectives, timelines, and assigned responsibilities."

In addition to their mentors' attentive guidance, mentees receive technical assistance throughout their 10-month experience. Mentees receive technical assistance in the form of in-person group, one-on-one guidance, and instructional sections at the winter and summer workshops as well as through webinars. Mentee teams receive travel support to attend winter and summer workshops. The winter workshop is held at in a location less likely to be impacted by winter weather and the location has varied from year to year depending on the results of a competitive bid process. The summer workshop is held in conjunction with the High Impact Technology Exchange Conference (HI-TEC). HI-TEC is a national conference held each summer that is produced by the NSF-ATE centers. With a focus on advanced technological education, HI-TEC is a conference where secondary and postsecondary educators, counselors, industry professionals, trade organizations, and technicians can update their knowledge and skills. Charged with Educating America's Technical Workforce, the event focuses on the preparation needed by the existing and future workforce for companies in the high-tech sectors that drive our nation's economy (High Impact Technology Exchange Conference, n.d.). The location of HI-TEC also varies from year to year within the US.

At both workshops, project staff, co-principal investigators, and other individuals with relevant expertise present information about the intricacies of the NSF-ATE grant application process. Workshop sessions cover the various components of a proposal as well as the mechanics necessary to preparation, such as formulating indirect costs and developing industry collaborations. Mentees not only hear about NSF-ATE review panels, but they also gain firsthand experience with the review process during a mock panel review session where both funded and declined NSF-ATE grant proposals are reviewed.

Project staff members provide ongoing technical support to mentees via a help desk, which accepts both calls and emails. In addition, the project runs a YouTube channel that serves as a repository for the archived and recorded technical assistance webinars it has created. Technical assistance webinars provide pertinent information, tips, templates, and examples to help assist potential grantees in preparing a budget, forms, and evaluation sections within their NSF-ATE proposal.

The webinars and other digital resources developed to inform mentees are available to all prospective NSF-ATE grantees at no cost. The keyword searchable, online library collection includes proposal samples, guides, tutorials, checklists, excerpts from NSF publications, other publications, and an extensive list of frequently-asked-questions with answers. As open resources on the project website, these materials are available to faculty and staff at any U.S. organization interested in preparing competitive NSF-ATE grant proposals.

\section{Mentee Selection}

During four consecutive years beginning in 2012, the project has accepted applications (due in October) from which it selects 20 colleges to receive mentoring and travel support for mentees to attend training during the first 10 months of the following year. To be eligible for the program, a 
college must have not received an ATE grant in the past 10 years or have never received one at all. To diversify the NSF-ATE applicant pool, the project team encourages applications from small colleges, rural colleges, and colleges that serve populations underrepresented in STEM fields. The team leaders target these three types of institutions because they have historically lacked the institutional capacity or personnel with the experience to encourage faculty to seek ATE-NSF funding; however, the Mentor-Connect project welcomes all eligible institutions to apply. The NSF-ATE program "encourages proposals from Minority Serving Institutions and other institutions that support the recruitment, retention, and completion of underrepresented students in technician education programs" (National Science Foundation, n.d.). Thus, to support NSF diversity goals, the diversity of the faculty team named in a college's application is also considered during the Mentor-Connect cohort selection process. NSF considers underrepresented minorities in STEM as American Indians, Alaska Natives, Blacks/African Americans, Hispanics/Latinos, and Native Hawaiians or other Pacific Islanders.

NSF's process for reviewing ATE grant applications and making awards means that it is common for six to nine months to elapse from the day a proposal is submitted until notification of a funding decision is received. The project guides prospective grantees (selected mentees) in understanding NSF's funding process and helps them through the proposal preparation process by providing technical assistance through workshops, webinars, and constant communication with project principal investigators and mentors. An illustration of this process is displayed below (Proposal and Award Policies, 2017).

Figure 1. NSF Proposal \& Award Process \& Timeline

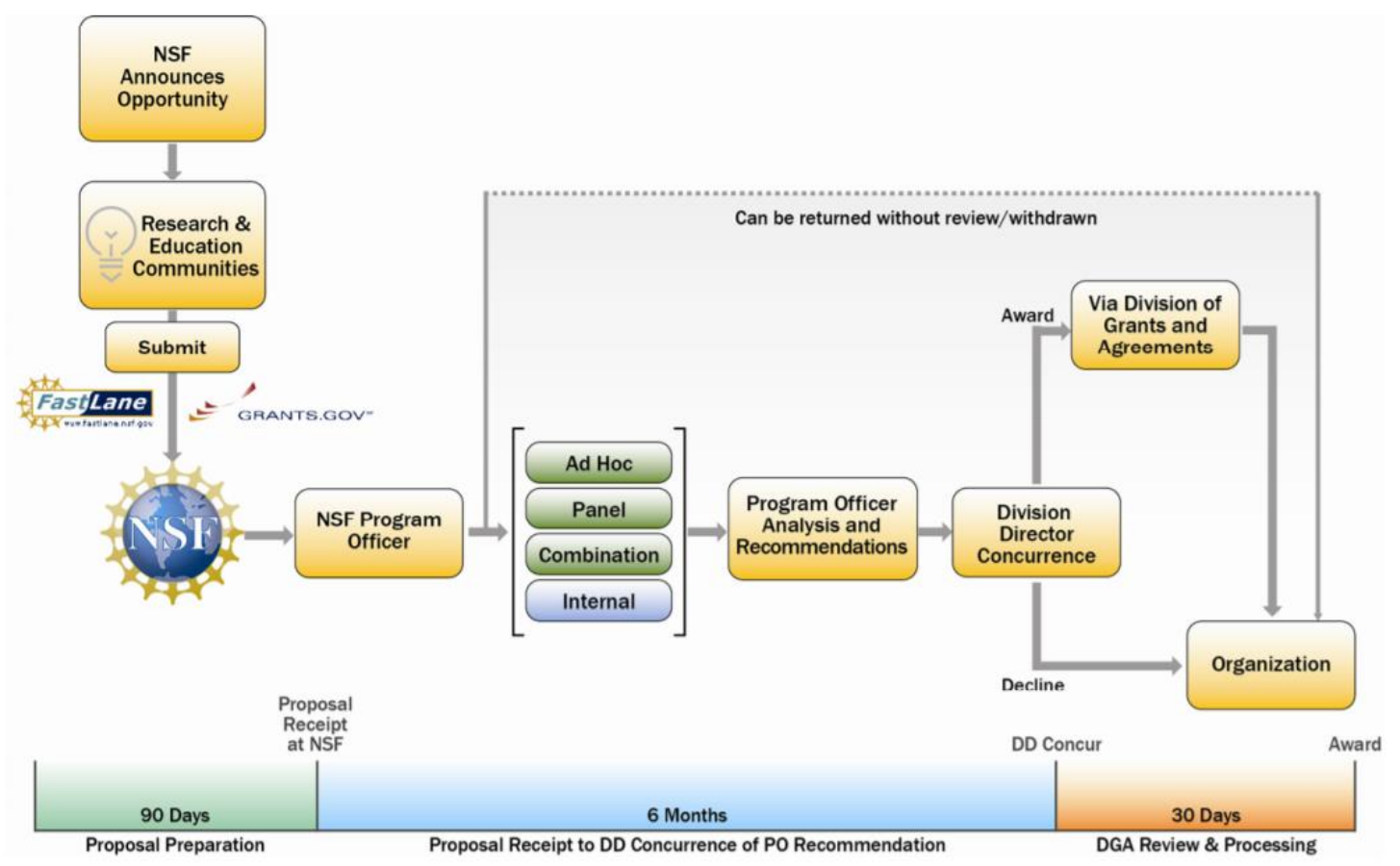

Methods: Materials 
The project's application is simple. The first step is a self-scored test of applicants' knowledge of the NSF-ATE solicitation (See Appendix C for Self-Assessment Test). The solicitation is a public document that explains the funding opportunity, proposal requirements, and submission process (National Science Foundation, 2016). The project team refers to this as a self-assessment because it expects college personnel who wish to be involved to evaluate whether they are ready to begin the process of developing an NSF-ATE proposal. The questions on the self-assessment are designed to stimulate careful study of the NSF-ATE grant solicitation. The application requires a 300-word statement from the college about the industry cluster or technical field that the two-person college team intends to target with the project it plans to propose to NSF-ATE. In addition, each faculty team member must submit a 200-word personal statement about his or her interest in participating in the mentoring experience. The final item in the application is an affidavit from a college administrator confirming the college's eligibility and intent to apply for an NSF-ATE Small Grant for Institutions New to the ATE Program track.

Applications are evaluated by the principal investigator and co-principal investigators according to a rubric that helps assess the likelihood that the college team can benefit from and be successful in this endeavor (See Appendix D for rubric). The rubric ratings consider whether a college is rural or minority-serving and if it has received other ATE-funded mentoring. Faculty attributes covered by the rubric include gender, race, ethnicity, years of academic experience, discipline, and teaching status (e.g., permanent/full-time or adjunct/part-time). Applicants are notified whether or not they have been selected for the current Mentor-Connect cohort in early November. For the five cohorts selected to date, the overall college acceptance rate for a cohort is $65 \%$. The acceptance rate has varied from cohort to cohort depending on the number of applicants each year. The table below (Table 1) shows the acceptance rates for applicants for each of the five cohorts.

Table 1

Application Acceptance Rate

\begin{tabular}{|c|c|c|c|c|c|c|}
\hline & $\begin{array}{c}\text { Cohort } \\
\mathbf{1} \\
(\mathbf{2 0 1 3})\end{array}$ & $\begin{array}{c}\text { Cohort } \\
\mathbf{2} \\
(\mathbf{2 0 1 4})\end{array}$ & $\begin{array}{c}\text { Cohort } \\
\mathbf{3} \\
(\mathbf{2 0 1 5})\end{array}$ & $\begin{array}{c}\text { Cohort } \\
\mathbf{4} \\
(\mathbf{2 0 1 6}\end{array}$ & $\begin{array}{c}\text { Cohort } \\
\mathbf{5} \\
(\mathbf{2 0 1 7})\end{array}$ & Overall \\
\hline $\begin{array}{c}\text { Applications } \\
\text { Received }\end{array}$ & 36 & 26 & 31 & 34 & 29 & 156 \\
\hline $\begin{array}{c}\text { Colleges } \\
\text { Accepted }\end{array}$ & 20 & 20 & $21 *$ & 20 & 20 & 101 \\
\hline $\begin{array}{c}\text { Selection } \\
\text { ratio* }\end{array}$ & $20 / 36$ & $20 / 26$ & $21 / 31$ & $\begin{array}{c}20 / 34 \\
59 \%\end{array}$ & $\begin{array}{c}20 / 29 \\
69 \%\end{array}$ & $\begin{array}{c}101 / 156 \\
65 \%\end{array}$ \\
\hline
\end{tabular}

*Note. An extra team was selected for Cohort 3 due to a tie in rubric scores for selection; selection ratio percentages have been rounded to the nearest whole number.

The first in-person activity for each cohort of STEM faculty teams from each selected college is the winter workshop that is held early in the year. This first convening of the cohort enables 
teams to meet and work with their mentor and learn about grant writing for the NSF ATE Program. The project provides travel support for two STEM faculty participants. The project participant selection process ensures that either of the individuals has qualifications to serve as the principal investigator of the ATE project that will be developed.

As a result of promising results among early cohort participants whose teams also included a college grant writer and/or an administrator, the project now encourages colleges to pay for additional personnel to attend the two-day winter workshop. Having a grant writer or administrator involved with the mentees from the outset seems to increase college buy-in and the likelihood the team will submit an NSF-ATE proposal. In a few instances, the larger teams have made it possible for proposal preparation to continue despite personnel turnover during the year.

To increase awareness of the project and NSF-ATE, project leaders participated in ten outreach events from 2013 to 2016. To encourage participation in NSF-ATE by specific audiences, project personnel participated in specially targeted programs for audiences made up primarily of faculty teaching underserved populations, diverse faculty (i.e. women and race and ethnic groups underrepresented in STEM), and grant writers.

\section{Mentor Selection}

In selecting mentors to work with potential grantees, the team uses a referral and recommendation process that taps into a pool of educators with many years of experience working in the NSF-ATE program. Among the mentors are principal investigators and directors of ATE national and regional centers, NSF-ATE project principal investigators, NSF proposal review panelists, and former NSF program officers. Potential mentors first complete interest profiles. If they seem to be a good match for mentees, they are asked to fill out a formal application unless they have previously served as a project mentor. Nineteen mentors have served to date. Six mentors have served as mentors for one year of the project, two mentors have served for two years, five have served for three years, two mentors have served for four years, and four mentors have served all five years since the project started.

Selected mentors agree to participate in all scheduled mentoring events and to provide 36 hours of one-on-one work with each of the two mentee teams assigned to them. This specified time span ensures that each team receives enough mentoring time to make a difference. It also protects mentors from teams that may be inclined to be too demanding. The mentor-mentee matches are not necessarily based on STEM field or geographic proximity. However, those are among the factors that the project's principal investigator and co-principal investigators consider when they assign mentees to mentors.

Mentors initially convene for a dinner meeting the evening prior to the start of the annual NSFATE Principal Investigators Conference, a fall conference organized by the American Association of Community Colleges (AACC), in which "key people working on ATE projects across the country" get together and focus on "critical issues related to advanced technological education" (AACC, 2016). This initial meeting with the project team and NSF program officers is followed by a mentor online orientation in mid-November. There is also a mentor meeting at the winter workshop. Guidelines and further clarification about expectations are provided, which 
are stated in more detail in the methods section. The guidelines list general expectations for mentors and mentees and offer tips for successful mentoring relationships.

Results - Geographic Diversity of Institutions

Applications have been strong in each of the five years of the program. Overall $65 \%$ of the 156 institutions that applied to the project have been selected for the mentoring experience. The 101 cohort teams have come from 31 different states. In the first year of the project, two colleges had two teams selected. Consequently, a total of 99 institutions have been involved in the first five cohorts. All of these institutions are in geographic areas where faculty or other college personnel were not previously engaged with the NSF-ATE program. The project references AACC classifications to identify whether a college is rural or serves an underserved or underrepresented student population. Colleges are not selected based on geographic location alone.

The map below shows the 31 states represented by the five cohorts of mentee teams selected from 2012 through 2016. Colleges from 12 states were in Cohort 1; colleges from 13 states (8 new) were in Cohort 2; colleges from 16 states (4 new) were in Cohort 3; colleges from 15 states ( 3 new) were in Cohort 4; and colleges from 18 states ( 4 new) were in Cohort 5, the current cohort.

Figure 2. States represented by the five cohorts of mentee teams selected $(2012-2016)$

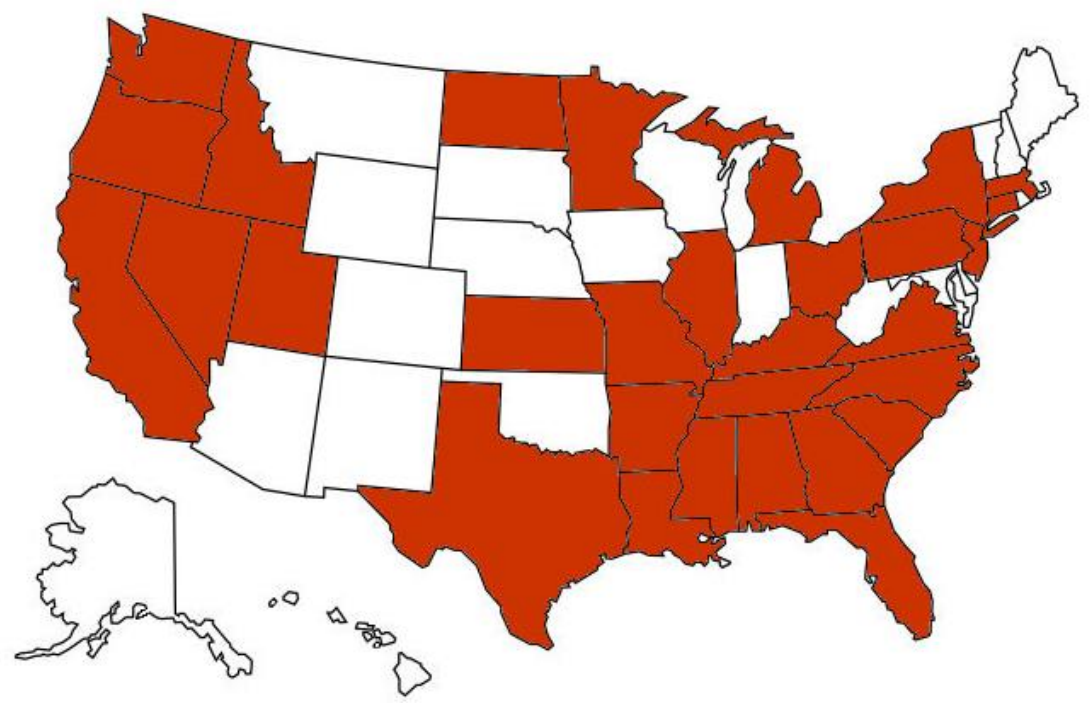

While the NSF-ATE program had awarded grants to institutions in every U.S. state and Puerto Rico before funding of this special project, analysis showed the distribution of those awards to be lopsided: a small group of institutions had received multiple awards whereas a far greater number of community and technical colleges had received none. So while all 50 states have had NSF-ATE grants since 1993, there were regions within most states where either colleges had never sought NSF-ATE grants or their grant proposals had not been successful. For example, in the state of Washington, NSF-ATE grant recipients had historically been concentrated in the metropolitan areas along the state's western coast. The project team specifically targeted colleges in the underserved eastern side of the state of Washington. Four teams from this area were in 
Cohort 1. The project evaluator has documented similar geographic diversity in other states and attributed the change to the project.

Results - Gender Balance and Ethnic Diversity

The STEM faculty leadership component of the initiative seeks to impact the diversity of the principal investigator pool. As part of this effort the project team is engaged in a longitudinal study of the geographic and demographic diversity of the colleges and individuals who participate over time. So far achieving gender balance and ethnic diversity has been constrained because STEM educators outside the biological sciences currently and historically employed at two-year institutions or colleges have been predominantly male and Caucasian.

To increase the participation of faculty members from underrepresented groups in STEM, the project team has initiated work with minority affiliate councils within AACC, such as the National Community College Hispanic Council (NCCHC), to encourage applications from minority-serving institutions and from minority faculty members.

The project team faces a similar challenge in its search for mentors from underrepresented groups. The most experienced principal investigators involved in the NSF-ATE program are predominantly Caucasian. To address this challenge, project leaders are initiating strategies to recruit and prepare mentors from among the more diverse pool of experienced ATE project coprincipal investigators or other project personnel.

Results - Proposal Submissions to NSF-ATE

Nearly all the colleges - $86 \%$ of the 81 colleges participating in the first four cohorts - submitted proposals to the NSF-ATE program. Submitting a competitive proposal to NSF-ATE is an important objective and the primary goal of teams working through the mentorship process.

Of the 54 colleges in the first three cohorts whose applications have been completely processed by NSF, 36 have been awarded grants of approximately $\$ 200,000$ each. This $67 \%$ success rate far exceeds ATE's usual funding rate of $22 \%$. However, it should be noted that mentorship project participants' success rate is heavily influenced by their submission to the Small Grants for Colleges New to ATE program.

The time lag for documenting project participant success is significant. Because mentee colleges submit proposals in October of the year in which they are a part of the mentorship, Cohort 4 colleges that submitted in October 2016 will not receive funding decisions from NSF until mid2017. Cohort 5 colleges will not submit until October 2017 (See Appendix E for more detailed information on the NSF-ATE Proposal and Award Process for funding).

Results - NSF-ATE Grant Awards

The monetary outcomes for the project are most accurately considered in the context of the funding for the Small Grants for Institutions New to ATE. As the NSF-ATE Solicitation (NSF 14-577) explains, within this track the agency awards "approximately 12 to 20 awards for up to 
$\$ 200,000$ (each)" every year (National Science Foundation, 2016). To help address the agency's diversity goals, the project selects participants for its project from institutions that are eligible for the small grants track. Leaders and mentors encourage participants to select this funding track. However, not all participants have followed this advice and as shown in the next chart. Participants submitting first-time proposals in the more competitive ATE Program funding tracks have not fared well. Those seeking higher levels of funding in the other ATE funding tracks face far greater competition.

In January 2017, participant funding results were available for Cohorts 1, 2, and 3, which were the cohort colleges submitting proposals in October 2013, 2014, and 2015, respectively. Table 2 below shows the Proposal Submission and Funding Outcomes Data for Cohort 1, 2, 3, and 4. Table 2

Proposal Submission and Funding Outcomes Data

\begin{tabular}{|c|c|c|c|c|c|c|}
\hline Cohort Colleges & $\begin{array}{c}\# 1 \\
(2013)\end{array}$ & $\begin{array}{c}\# 2 \\
(2014)\end{array}$ & $\begin{array}{c}\# 3 \\
\text { (2015) }\end{array}$ & $\begin{array}{c}\# 4 \\
(2016)\end{array}$ & $\begin{array}{c}\text { \# Project } \\
\text { Colleges }\end{array}$ & $\begin{array}{l}\text { Succes } \\
\text { s Rate }\end{array}$ \\
\hline $\begin{array}{l}\text { Colleges Selected for } \\
\text { Project Cohort }\end{array}$ & 20 & 20 & 21 & 20 & 81 & \\
\hline $\begin{array}{c}\text { Cohort Colleges that } \\
\text { Submitted NSF-ATE } \\
\text { Proposals }\end{array}$ & 18 & 18 & 18 & 16 & 70 & $\begin{array}{l}70 / 81 \\
86.4 \%\end{array}$ \\
\hline $\begin{array}{l}\text { Cohort Colleges that } \\
\text { Submitted to Small } \\
\text { Grants for Colleges } \\
\text { New to ATE Track }\end{array}$ & 14 & 16 & 17 & 16 & 63 & $\begin{array}{l}63 / 70 \\
90 \%\end{array}$ \\
\hline $\begin{array}{c}\text { NSF Awards to } \\
\text { Cohort Colleges in the } \\
\text { Small Grants for } \\
\text { Colleges New to ATE } \\
\text { Track }\end{array}$ & 10 & 12 & 14 & (pending)* & 36 & $\begin{array}{c}36 / 54 \\
67 \%\end{array}$ \\
\hline $\begin{array}{c}\text { Cohort Colleges that } \\
\text { Submitted to Other } \\
\text { ATE Tracks }\end{array}$ & 4 & 2 & 1 & 0 & 7 & \\
\hline $\begin{array}{l}\text { NSF Awards to Cohort } \\
\text { Colleges that } \\
\text { Submitted to Other } \\
\text { ATE Tracks }\end{array}$ & 0 & 0 & 0 & $\mathrm{n} / \mathrm{a}$ & 0 & $\begin{array}{l}0 / 7, \\
0 \%\end{array}$ \\
\hline
\end{tabular}

*Note. Cohort 4 will not receive notification of funding until mid-2017; Cohort 5 (2017) is not listed in chart because cohort colleges will not submit until fall 2017.

These data show that those submitting proposals to the NSF-ATE Program for the first time are significantly more likely to be successful in winning one of the estimated 12 to 20 awards made in the small grants funding track each year. It is important to note that the Small Grants for Colleges New to ATE proposals are reviewed separately and compete only with other small 
grant proposals. Historically, the funding rate in this track is 60 to $70 \%$. However, the overall ATE rate is $22 \%$.

Nevertheless, the data provide evidence that training and support provided by the MentorConnect project are affecting in positive ways both college capacity and faculty member skills to submit competitive proposals in the small grants track. Other funding tracks within ATE are more competitive, and the program's overall funding rate of $22 \%$ is lower than for the small grants track that has historically ranged from 60 to $70 \%$. For all tracks, the number of awards made by NSF-ATE each year and funding rates are influenced by the overall budget for the program, the number of proposals submitted for consideration, and the quality of proposals.

Results - Mentees' Feedback

The feedback mentees have provided on project evaluations has been quite positive. The following quotations from 2015 mentees' evaluations are typical of mentees' comments from all the cohorts:

"Invaluable experience! Great working with our mentor. She was a wealth of knowledge and put us in touch with many resources to further our project."

"I love you all. I love this mentorship program. You have been sooooo helpful!"

"[The project] has been extremely valuable throughout the process. We really appreciate all that you've done."

Mentees have offered suggestions for improvements, but the majority of mentees have given the project high ratings. For example, $90 \%$ of the 32 mentees who completed surveys after the January 2015 workshop rated the pre-workshop homework as a 4 (Great Value) or 3. None of the mentees rated any workshop component as a 1 (Little Value). All ratings were based on a 1 to 5 scale. One mentee statement summarizes the project's potential to instigate improvements in STEM programs and transform faculty into STEM leaders: "If it weren't for this event [workshop], I would have zero chance of receiving a grant. I now understand what to do and expect. I feel a lot more confident to move forward."

Conclusion and Future Considerations

Through the effective use of experienced ATE principal investigators as mentors, projectprovided technical assistance and training, and strategic development of ATE-specific grantwriting digital resources, this unique project has expanded the number of community colleges engaging with the NSF-ATE program. The project has expanded awareness of NSF-ATE among previously non-participating technical and community colleges and increased the geographic diversity of the institutions submitting proposals to the NSF-ATE program. The project has facilitated knowledge transfer from mentors to prospective NSF-ATE principal investigators, improved the quality of proposals being submitted in the Small Grants for Institutions New to the ATE program, and is cultivating leadership skills among mentees. 
A significant contributor to the high funding success rate of cohort colleges is based on the Mentor-Connect faculty development process. It involves a rigorous process for intake and selection of participants, guidance for mentors, the systematic implementation of a mentoring protocol, creation of online reference materials, participant instruction, and technical support to mentors, mentees, and all cohort participants. Analysis of impact is an on-going process. A longitudinal study that will be completed in 2020 will provide information about the project's impact on the NSF-ATE program and technician education in general.

The long-term expectation is that the stronger, funded proposals that result from the project will improve STEM technician programs and develop more highly qualified technicians to meet the nation's workforce needs. In addition, replicable models for promoting success of community colleges in the competitive arena of National Science Foundation grant funding and developing future STEM faculty leaders are emerging and may be applied to other NSF funding programs. 
References

American Association of Community Colleges (AACC). (2016). ATE Conference 2016. Retrieved from http://www.aacc.nche.edu/Resources/aaccprograms/ate/conf2016/Pages/default.aspx

ATE Central, About the ATE Program. Retrieved from https://atecentral.net/aboutate

Merisotis, J.P., \& Wolanin, T.R. (n.d.). Community College Financing: Strategies and Challenges. Retrieved from http://www.aacc.nche.edu/Resources/aaccprograms/pastprojects/Pages/ccfinancing.aspx

Mitchell, M. \& Leachman, M. (2015, May 13). Years of Cuts Threaten to Put College Out of Reach for More Students. Retrieved from Center on Budget and Policy Priorities website http://www.cbpp.org/research/state-budget-and-tax/years-of-cutsthreaten-to-put-college-out-of-reach-for-more-students

Murrell, A.J., Forte-Trammell, S., and Bing, D. (2008). Intelligent Mentoring: How IBM Creates Value through People, Knowledge, and Relationships. Indianapolis, Indiana: IBM Press.

High Impact Technology Exchange Conference, About HI-TEC. Retrieved from http://www.highimpact-tec.org

National Science Foundation. (2016). Advanced Technological Education Program Solicitation (NSF 14-577.) Retrieved from https://www.nsf.gov/pubs/2014/nsf14577/nsf14577.htm

National Science Foundation. (n.d.). Advanced Technological Education (ATE). Retrieved from https://www.nsf.gov/funding/pgm_summ.jsp?pims_id=5464

National Science Foundation. (2017). Proposal and Award Policies and Procedures Guide (NSF Publication No. 17.1) Retrieved from https://www.nsf.gov/pubs/policydocs/pappg17_1/nsf17_1.pdf

Wilson, L. N., Wingate, L. A., Lee, M. J., \& Gullickson, A. (2016). ATE Annual Survey: 2016 Report. Kalamazoo, MI: The Evaluation Center, Western Michigan University. Retrieved from http://www.evalu-ate.org/annual_survey/ 
Appendix A

Mentor: Hints for a Successful Mentoring Relationship

1. Communication - maintain frequent and open lines of preferred communication with your mentee(s) and key stakeholders. Schedule regular meetings at "best" times for all. Initiate contact with college team if needed.

2. Care-demonstrate concern for your teams and their projects to develop rapport and confidence.

3. Involvement level - maintain a balance between passivity and direction. Seek a balance that is acceptable to you and the mentees and their stakeholders. Listen, question, and respond as needed.

4. Diversity - understand the uniqueness and differences in types of individuals, institutions, resources, or maturity of programs of your mentee team. Get beyond your own situation and experiences by taking a larger point of view. Share what is pertinent from your experience, but be sensitive about over-relating what you have done at your college.

5. Reinforce role boundaries-beware of taking on the mentees' institutional problems. Help them figure out how to best address and resolve issues that arise that affect their project and proposal, rather than fixing it yourself.

6. Flexibility - be systematic but not rigid in your approach to your mentee team. Have a clear plan of what you want to see happen at each stage, but be adaptable. Be sensitive to the different learning styles of you and your college team members.

7. Politics \& Cultures - remember that nearly every project has a political/cultural component that will need to be addressed. History, factions, people, and power relations can have more influence on project success than reason, merit, or justification. Consideration of real politics is unavoidable and should not be treated as irrelevant gossip, but care should be taken not to involve yourself too directly in helping your mentee team address this component.

8. Process - help your college teams consider not only the "what" of their activities, but also the "how." Help your teams emphasize community building and positive relationship building within and across various stakeholders.

9. Content - although negotiating the process of institutional innovation and implementation is important, keep the content objective in view. Remember the overriding project goals: to help colleges develop or strengthen technician training programs in science, technology, engineering, and mathematics fields by submitting a successful proposal. Good proposals tell 
a consistent story complemented by clear, specific and achievable goals, objectives, timelines, and assigned responsibilities.

\section{Appendix B}

Mentee: Hints for a Successful Mentoring Relationship

1. Communication - maintain frequent and open lines of preferred communication with your mentor, team members, and key stakeholders. Schedule regular meetings at "best" times for all.

2. Respect-show appreciation for your mentor's experience, his/her willingness to share their expertise, and their perspectives on creating a successful ATE project. The same is true for your other team members.

3. Preparation-be prepared for mentor meetings. Keep ahead of tasks and timelines and be willing to listen, question, and respond as fully as possible. Make sure your project needs are articulated clearly and understood fully by all involved.

4. Openness - be open to other points of view and appreciate the "big picture" of the ATE program nationally. Since every college is different, there will be no single perfect model; input from other perspectives and experiences may help improve your effort.

5. Optimism - don't expect your mentor to know how to fix every problem for you. Be open to change or innovation and to new strategies, if necessary. Look for solutions.

6. Flexibility-have a clear plan of what you want to see happen at each stage, but be adaptable. Be sensitive to the different learning styles of your college team members and your mentor.

7. Change is inevitable. Pay attention to the suggested timelines as you make necessary changes.

8. Politics \& Culture - be realistic about history, factions, people, and power relations that can affect your project positively or negatively. Your mentor can help strategize about how to address these issues, but it's not his/her job to fix them for you.

9. Process -work with your mentor to help your college team members consider not only the "what" of their activities, but also the "how." Help your team members emphasize community building and positive relationship building within and across various stakeholders.

10. Content-remember the overriding Mentor-Connect and NSF-ATE project goal is to help colleges develop or strengthen technician training programs in science, technology, engineering, and mathematics fields by developing a project that merits NSF funding. Good 
proposals tell a consistent story complemented by clear, specific and achievable goals, objectives, timelines, and assigned responsibilities.

\section{Appendix C}

Technical Assistance for Prospective Principal Investigators National Science Foundation, Advanced Technological Education Program (NSF ATE) www.nsf.gov/ate to access current NSF-ATE solicitation Readiness Self-Assessment

This is a self-scoring instrument meant to quickly and easily demonstrate your readiness to develop a proposal in the Small Grants for Institutions New to ATE funding category. Program Officers report that proposals are most often rejected because the applicants have not addressed the criteria in the solicitation. This self-assessment will stimulate a thorough review of the program solicitation, which in turn will contribute to your grant-writing success.

The questions on this self-assessment relate to specific information in the NSF-ATE Program Solicitation, 14-577. This solicitation expires October 2016. This self-assessment will be revised thereafter to reflect any changes incorporated in the new solicitation. Please read and review the rules, regulations, and stipulations in the applicable solicitation for the date of your proposal submission. Read it early and revisit it often for improved chances of success with your grant proposal development and submission.

1. What is the maximum amount of funding that can be requested in the "Small Grants for Institutions New to ATE" category?
a. $\$ 2,000$
b. $\$ 2,000,000$
c. $\$ 200,000$
d. $\$ 20,000$

2. First-time applicants to NSF-ATE are encouraged to consider which type of ATE funding?
a. Planning grant
b. Small Grants for Institutions New to the ATE Program
c. Regional ATE center
d. National ATE center

3. What is the maximum duration that can be requested for an ATE Project?
a. 3 months
b. 72 months
c. 30 months
d. 36 months 
4. For an ATE project, the project leadership team (Principal Investigator, Co-Principal Investigator(s), and /or Senior Personnel) must include which of the following?
a. Research university faculty
b. Community college faculty
c. Secondary school teacher(s)
d. Industry partner(s)

5. How many Principal Investigators (PIs) does NSF recognize for a given NSF-ATE grant?
a. 1
b. 2
c. 3
d. 5

6. Who is your main contact at NSF during the proposal development and submission process?
a. A science associate at the National Science Foundation
b. The FastLane help desk at NSF
c. Any program officer at NSF
d. A program officer from the list of contacts provided for the NSF-ATE program

7. Which of the following is not a required component when submitting a NSF-ATE grant proposal?
a. Project description
b. Roster of participating faculty
c. Data management plan
d. Project summary

8. What is the page limit for the proposal Project Summary?
a. 1 page
b. 2 pages
c. 5 pages
d. 3 pages

9. In what month(s) of the year are proposals due in response to the ATE Program solicitation?
a. April
b. July
c. October
d. April and October

10. GPG stands for:
a. Great Program Guide
b. Good Pathways Guide
c. Grant Proposal Guide
d. Government Procurement Guide 
11. Which of the following is NOT included in the Award Information provided in the NSFATE Program Solicitation?

a. Estimated number of awards per year

b. Estimated funding Congress has allocated

c. Estimated number of first-time applicants to NSF-ATE

d. Estimated funding allocated for grant partners

12. There are 3 major categories for NSF-ATE proposals. Which of the following is NOT one of those categories?
a. ATE project grants
b. ATE center grants
c. ATE targeted research grants
d. ATE collaborative consortium grants

13. Which of the following may NOT be included in an ATE proposal?
a. Faculty travel
b. Student recruitment
c. The modification, construction, or furnishing of laboratories or other buildings
d. Curriculum revisions

14. What guidance does NSF-ATE provide for including references in a proposal?
a. References should be explained in the project description and are also required to be listed separately.
b. References may be embedded and explained in the project description but do not need to be listed separately.
c. References are optional for NSF-ATE proposals.
d. References are not to be included in the project description, but should be listed separately.

15. In preparing the required Budget and a Budget Justification for a proposal, NSF-ATE provides direction on all but which of the following topics?
a. Voluntary committed cost sharing
b. Budget justification for consultants
c. Budget allocation for project evaluator
d. Page limit for a budget justification

16. Which of the following is true about "committed cost sharing" in an NSF proposal/proposal budget?

a. Cost sharing can be included as an unrequested portion of the college's federallynegotiated indirect cost rate.

b. Cost sharing will make your proposal more competitive.

c. Cost sharing is encouraged but is not a mandatory requirement.

d. Voluntary committed cost sharing is specifically prohibited.

17. The Project Summary should address the disciplinary focus (or foci) of the proposed project, the kinds of activities to be undertaken, and the primary audience to be affected 
by those activities. What else must be explicitly addressed in the Project Summary in separate statements?

a. Intellectual merit and broader impacts

b. Project goals and broader impacts

c. Intellectual merit and anticipated research outcomes

d. The name of the Principal Investigator and anticipated impacts on STEM workforce development

18. The online NSF system through which ATE proposals are submitted is called:
a. Research.gov
b. FastLane
c. Grants.gov
d. SureSubmit.com

19. The person who is authorized to submit a grant proposal electronically for your institution to the National Science Foundation is:
a. The chairman of the board
b. The Sponsored Research Officer (SRO)/ Grants Director
c. The Principal Investigator (PI)
d. The VP of Institutional Advancement

20. What is the normal amount that may not be exceeded for equipment purchases included in a NSF-ATE budget (when the equipment being requested clearly supports and is required for the work of the project)?
a. $\$ 50,000$
b. $\$ 100,000$
c. $10 \%$ of the overall budget request
d. $\$ 200,000$

21. What is the smallest acceptable font size for an NSF-ATE Small Grant Proposal?
a. 4.5 pt. font
b. 10 pt. font
c. 12 pt. font
d. 16 pt. font

\section{Instructions for Self-Scoring}

- Give yourself 1 point for each correct answer.

- Your total determines your score on this self-assessment, and lets you know if you're ready or not to move ahead. Keep re-taking until you have confidence in your ability to navigate and apply information from the NSF-ATE Program Solicitation.

\section{7-21 Correct Answers}

Congratulations! You have demonstrated that you understand the program solicitation well enough to move forward with developing a proposal. You should continue to revisit the solicitation regularly during the grant development process.

\section{2-16 Correct Answers}


You did well but should take note of the sections of the solicitation that cover topics for which you selected an incorrect answer. You should continue to revisit the solicitation regularly during the grant development process.

\section{8-11 Correct Answers}

You missed some key points in the solicitation and should read it again thoroughly, with particular attention to sections that address questions for which you selected an incorrect answer. You should continue to revisit the solicitation regularly during the grant development process.

\section{0-7 Correct Answers}

Perhaps you have not read the solicitation recently or you did not read it carefully. To be successful, you should spend time reading and understanding this document. You may re-take this assessment at any time to check your understanding. Once you have increased your knowledge of the solicitation, you should continue to revisit this publication regularly during the grant development process.

\section{Readiness Self-Assessment KEY to Correct Answers}

1. $\mathrm{C}$

2. B

3. D

4. B

5. A

6. D

7. B

8. A

9. $\mathrm{C}$

10. C

11. D

12. D

13. $\mathrm{C}$

14. A

15. C

16. D

17. A

18. B

19. B

20. D

21. B 
Appendix D

Mentor- Connect Applicant Rating Rubric

\# of Applicant Institutions:

\section{Points}

assigned

AACC Rural Classification (max. +2)

\begin{tabular}{|l|l|l|l|}
\hline Yes & & 2 \\
\hline No & & 0 \\
\hline
\end{tabular}

State not yet served by $\mathrm{M}-\mathrm{C}(\max +2)$

\begin{tabular}{c|c|c}
\hline \multicolumn{1}{|l|}{ Yes } & 2 \\
\hline No & & 0 \\
\hline Previous Mentor-Links? (max. +2) & \\
\hline Yes & 2 \\
\hline No & 0 \\
\hline Previous Mentor-Connect? (max. +2) & 2 \\
\hline Yes & 2 \\
\hline No & & 0
\end{tabular}

Statement of Interest (max. +14)

Technician education focus $\quad 0-4$

Workforce need articulated 0-4

Clear description of idea 0-4

Reference to partnerships 2

Faculty Team Members (max. +44)

\begin{tabular}{|l|l|l} 
Team Gender Mix & & \\
\hline 2 Females & & 2 \\
\hline 1 Female & & 1 \\
\hline Other & & 0 \\
\hline Race/Ethnicity & & \\
\hline 2 Hispanic; or not white,not Asian & 2 \\
\hline
\end{tabular}




\begin{tabular}{|c|c|c|}
\hline \multicolumn{3}{|l|}{ Race/Ethnicity } \\
\hline \multicolumn{2}{|c|}{2 Hispanic; or not white, not Asian } & 2 \\
\hline & 1 Hispanic; or not white,not Asian & 1 \\
\hline \multicolumn{2}{|c|}{ Team Discipline Mix } & \\
\hline \multicolumn{2}{|c|}{2 "ATE"engr/technology/sci } & 2 \\
\hline \multicolumn{2}{|c|}{1 "ATE", 1 gen science/math } & 1 \\
\hline \multicolumn{2}{|c|}{2 gen science or math } & 0 \\
\hline \multicolumn{2}{|l|}{ Employment } & \\
\hline \multicolumn{2}{|c|}{2 permanent faculty } & 2 \\
\hline \multicolumn{2}{|c|}{1 permanent/1adjunct } & 1 \\
\hline 2 adjur & & 0 \\
\hline \multicolumn{3}{|c|}{ Experience Teaching } \\
\hline \multicolumn{2}{|c|}{2 faculty checked 5-6 or 7-10 } & 2 \\
\hline \multicolumn{2}{|c|}{1 faculty checked $5-6$ or $7-10$} & 1 \\
\hline \multicolumn{2}{|c|}{0 faculty checked $5-6$ or $7-10$} & 0 \\
\hline \multicolumn{2}{|c|}{ Expericence at Institution } & \\
\hline \multicolumn{2}{|c|}{2 faculty checked 5-6 or 7-10 } & 2 \\
\hline \multicolumn{2}{|c|}{1 faculty checked $5-6$ or $7-10$} & 1 \\
\hline \multicolumn{2}{|c|}{0 faculty checked $5-6$ or $7-10$} & 0 \\
\hline \multicolumn{3}{|c|}{ Faculty Statement 1 -[Last Name] } \\
\hline \multicolumn{2}{|c|}{ Technician education focus } & $0-4$ \\
\hline \multicolumn{2}{|c|}{ Student focus } & $0-4$ \\
\hline \multicolumn{2}{|c|}{ High-level interest } & $0-4$ \\
\hline \multicolumn{2}{|c|}{ Previous grant experience } & $0-4$ \\
\hline \multicolumn{3}{|c|}{ Faculty Statement 2 -[Last Name] } \\
\hline \multicolumn{2}{|c|}{ Technician education focus } & $0-4$ \\
\hline \multicolumn{2}{|c|}{ Student focus } & $0-4$ \\
\hline \multicolumn{2}{|c|}{ High-level interest } & $0-4$ \\
\hline & Previous grant experience & $0-4$ \\
\hline
\end{tabular}




\section{Appendix E}

\section{NSF Proposal and Award Process}

\section{PHASE I - PROPOSAL PREPARATION AND SUBMISSION - 90 DAYS}

1 - Opportunity Announced. All funding opportunities are announced on the NSF website. Grants.gov is another source for finding and applying for NSF funding. Program Descriptions, Program Announcements and Program Solicitations are mechanisms used by NSF to generate proposals. Unsolicited proposals to specific NSF programs may be submitted at any time.

2 - Proposal Submitted. The Grant Proposal Guide (GPG) is the source for guidance on preparing and submitting a proposal to NSF. The GPG details formatting and submission requirements. Applicants using Grants.gov must follow the guidelines in the NSF Grants.gov Application Guide. The proposing organization submits the proposal to NSF via either the NSF Fastlane System or via Grants.gov.

3 - Proposal Received. Proposals are received by the NSF Proposal Processing Unit and are assigned to the appropriate program for acknowledgement and, if they meet NSF requirements, for review. A proposal may be returned without review if it does not meet NSF proposal preparation requirements, such as page limitations, formatting instructions, and electronic submission, as specified in the GPG or program solicitation. The GPG identifies all of the reasons for which a proposal may be returned without review.

\section{PHASE II - PROPOSAL REVIEW AND PROCESSING - 6 MONTHS}

4 - Reviewers Selected. Reviewers are selected based on their specific and/or broad knowledge of the science and engineering fields; their broad knowledge of the infrastructure of the science and engineering enterprise, and its educational activities; and to the extent possible, diverse representation within the review group. Sources of reviewers can come from the program officer's knowledge of the research area; references listed in the proposal; recent professional society programs; computer searches of science and engineering journal articles related to the proposal; reviewer recommendations included in proposal or sent by email. Proposers are invited to suggest persons they believe are especially well qualified to review the proposal, as well as identify persons they would prefer not review the proposal.

5 - Peer Review. All NSF proposals are reviewed through use of the two NSB-approved merit review criteria: Intellectual Merit and Broader Impacts. Some solicitations may have additional review criteria. External reviewers' analyses and evaluation of the proposal provide information to the NSF Program Officer in making a recommendation regarding the proposal.

6 - Program Officer Recommendation. After scientific, technical and programmatic review, the NSF Program Officer recommends to the cognizant Division Director whether the proposal should be recommended for an award or declined for funding. Due to the large number of proposals received, the review and consideration process can take up to six months. Large or particularly complex proposals may require additional review and processing time.

7 - Division Director Review. If the decision is made to decline the award, the organization is notified and review information is available in the Fastlane System. If the decision is to award, the recommendation is submitted to a Grants \& Agreements Officer in the Division of Grants and Agreements (DGA).

\section{PHASE III - AWARD PROCESSING - 30 DAYS}

8 - Business Review. The Grants and Agreements Officer In the Division of Grants and Agreements (DGA) conducts a review of business, financial, and policy implications. Generally, DGA makes awards within 30 days after the program office makes its recommendation. Additional processing time may be required if: the organization has not received prior funding: if the award is a cooperative agreement; or it involves special situations (such as coordination with another Federal agency or a private funding source).

9 - Award Finalized. The award itself is comprised of an award notice, budget, proposal, applicable NSF conditions, and any other documents or requirements incorporated by reference into the agreement. Each NSF award notice specifically identifies certain conditions that are applicable to, and become part of, that award. 